Review Article

\title{
Relationship between the Dynamic Parameters of a Structure's Vibration Process and the Loading Model Moving on a Bridge
}

\author{
Thanh. Q Nguyen $\mathbb{1}^{1,2}$ \\ ${ }^{1}$ Faculty of Engineering and Technology, Thu Dau Mot University, Thu Dau Mot, Binh Duong, Vietnam \\ ${ }^{2}$ Thu Dau Mot University, Thu Dau Mot, Binh Duong, Vietnam \\ Correspondence should be addressed to Thanh. Q Nguyen; nguyenquangthanh@tdmu.edu.vn
}

Received 20 May 2021; Revised 23 June 2021; Accepted 22 July 2021; Published 2 August 2021

Academic Editor: Igor Pesko

Copyright ( 2021 Thanh. Q Nguyen. This is an open access article distributed under the Creative Commons Attribution License, which permits unrestricted use, distribution, and reproduction in any medium, provided the original work is properly cited.

A sufficiently strict conduction of supervision during bridge operation is a crucial matter for many countries, including the underdeveloped country of Viet Nam. In recent times, the budgets in developed countries used for funding the implementation of quality-assessment procedures are quite high compared to the lower budgets in underdeveloped countries. The plan proposed in this work addresses the current lack of information available in the process of structure-quality evaluation. The vibration signals will be acquired from the random circulation status to determine the structure's behavior so as to utilize the signal information during the bridge span's operation. The study's main goal is to find various parameters that can be used to evaluate the actual bridge performance. These parameters must meet certain criteria, such as high sensitivity, low measurement cost, and efficiency in the measurement process, but must not affect the itinerary of vehicles moving on the bridge. The actual structural vibration signals used in this work currently serve as a best trend model for evaluating the operation of the bridge span structure. This study will focus on determining the relationship among deflection, acceleration, and vehicle load so as to evaluate the structure's working process. This study has also fabricated an experimental model to evaluate and test the sensitivity of the parameters utilized in this study in order to verify the results obtained. The results obtained in this research will be applied for the quality-control process in several bridge models with span structures built with the composite steel concrete cross section of the beam. Many developing countries, including Viet Nam, will receive benefit in the future from the useful advantages presented in this study.

\section{Introduction}

Viet Nam is similar to other Southeast Asian countries [1, 2] located in the region, in that it has an interlace system of rivers and canals. Most major cities in Viet Nam are located in areas near rivers or river junctions. After conducting extensive surveys in the Ho Chi Minh City area [3, 4], it was determined that there are more than 1000 bridges $[5,6]$ and safe operations of these bridges are especially considered as a key focus because of their important role in so many socioeconomic activities. The normal measures of assessing the quality conditions of the bridge structure will be undertaken through an assessment of the bridge structure's concrete beams and the composite steel concrete cross section of the beam $[7,8]$. At present, the inspection, monitoring, and verification of bridge quality are commonly implemented through three main measures as follows: (i) The first measure is a system of human monitoring, giving information that is often more qualitative than quantitative, and that can be somewhat subjective. The techniques of this measure include inspection and monitoring by manual methods, visual inspection, and use of specialized equipment [9-11]. This measure has significant advantages and is simple and easy to implement, and the inspection cost for initial investment is low, but it has disadvantages as well: the damages in the details of the bridge structure cannot be detected in a timely fashion, and the bridge material mechanical changes cannot be evaluated. Most of the information obtained from a structure with these methods is of a qualitative nature, acquired through the subjective evaluation of human observations. 
(ii) The second measure consists of methods for collecting quantitative data for bridge vibrations generated by an applied periodic force. The bridge quality inspection [12-14] includes the following activities: the quality is either merely checked or thoroughly determined, the project quality is formally assessed, and the quality is compared to the design's original requirements. The aim of this measure is to assess the bridge's actual working ability under the actual load effect. Some parameters are used for a quantitative evaluation process during implementation [15], including deformation, deflection, vibration amplitude, and specific frequency. The advantage of this measure is that it can give us a clear understanding of the different quantitative values and the load's impact options. These methods can shed light on the factors responsible for putting the structure in some of the most dangerous situations during its operation. This measure's disadvantage is that the measurement data are obtained in a static state, except for few of the following dynamic parameters: specific frequency, damping coefficient, and vibration amplitude, which are determined by generating the vibration pattern with a periodic force. The amount of information received from this method is too low; therefore, it cannot fully reflect the operation status of the structure, nor fully explain the structure's behavior.

(iii) The third measure surveys the structure's behavior during the actual operation through vibration measurement [16-19]. This measure has been widely applied to bridge abutments in recent times. This measure allows the acquisition of much data regarding bridge behavior under diverse actual loads. This measure allows the advantages of characterizing the actual situation of the load, detecting changes in mechanical parameters, locating weakened portions of the structure, and determining the weakening rate over time. These advantages can help in making reasonable decisions and plans when evaluating a project's quality. However, for the cases of difficult economic situations in underdeveloped countries, these testing systems are not economically feasible and so cannot be widely applied.

Assessing the advantages and disadvantages of all three methods above, this study proposes several methods for building relationships between important parameters in the bridge structure's vibration process so as to collect data for the vibrations and deformation of the structure under the effects of random loads during operation and utilization. The data obtained in this study will supplement the bridge's existing database system and, at the same time, will add new parameters having a higher sensitivity than traditional parameters. This can serve in making the most suitable plan for quality assessment, inspection, and regular maintenance for a project. This study has practical significance in monitoring and evaluating a project's working status over time. This study also helps management agencies form a basis for making important decisions about the structure's operation. Furthermore, the results in this study, which have been implemented in practice, will establish a database source facilitating the application of these advanced methods in quality assessment and project management. This is the basis for expanding these research methods and conducting future bridge evaluations.

\section{Theoretical Basis}

Many studies have already carried out the modeling of bridge structures, which are categorized by type according to the structure's bearing status. Many models have simulated the structure of a bridge span in the form of force-bearing beams, models which are presently popular [20-22]. For a load applied under static conditions, the span structure model is generally depicted as shown in Figure 1.

For the case of the span model shown in Figure 1, if $P$ is the static load, the beam's deflection $y$ is given by the following formulas as

$$
y= \begin{cases}\frac{P b z}{6 E J l}\left(l^{2}-z^{2}-b^{2}\right), & 0 \leq z \leq a, \\ \frac{P a(l-z)}{6 E J l}\left(2 l z-z^{2}-a^{2}\right), & a \leq z \leq l,\end{cases}
$$

in which $l$ is the length of the beam and $a$ and $b$ are the positions to determine the set point of the load $P$. EJ is the flexural stiffness; $E$ is the elastic modulus; $P$ is the load on the beam; and $J$ is the area inertia moment to the principal axis of inertia, which is coincident with the $x$-axis direction.

If the load $p$ moves with speed $v$ along the beam length with $Q=Q_{0} \cos (\Omega t)$, as shown in Figure 2, the beam's forced vibration is demonstrated through the deflection equation, shown as follows:

$$
\begin{aligned}
y= & \frac{2 g P l^{3}}{A \gamma \pi^{2}} \sum_{i=1}^{i=\infty} \frac{\sin i \pi x / l}{i^{2}\left(i^{2} \pi^{2} a^{2}-v^{2} l^{2}\right)} \sin \frac{i \pi x}{l} \\
& -\frac{2 g P l^{4} v}{A \gamma \pi^{3} d} \sum_{i=1}^{i=\infty} \frac{\sin i \pi x / l}{i^{3}\left(i^{2} \pi^{2} a^{2}-v^{2} l^{2}\right)} \sin \frac{i^{2} \pi^{2} a t}{l^{2}},
\end{aligned}
$$

where $g$ is the gravity acceleration, $\rho$ is the specific weight per structure's unit volume, $A$ is the cross-sectional area, $d=\sqrt{E J / A \rho}$, and $t$ is the time. The forces actually acting on the structure are, however, often in the form of a harmonic force.

For the case shown in Figure 3, in which $Q$ is the variable force given by the expression $Q=Q_{0} \cos \Omega t$ and moving with speed $v$, the beam's forced vibration $[23,24]$ is presented as follows: 


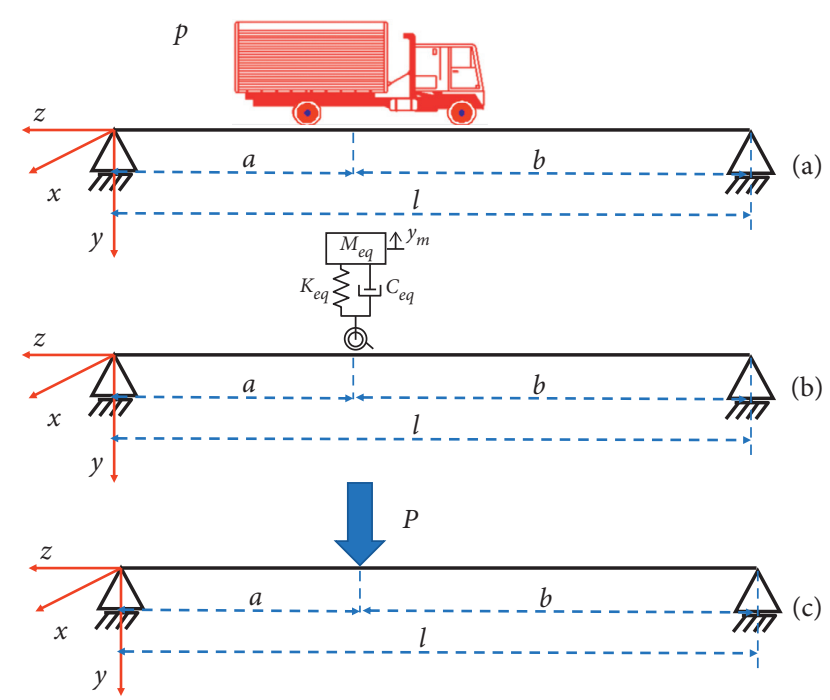

Figure 1: Single beam borne with static load.

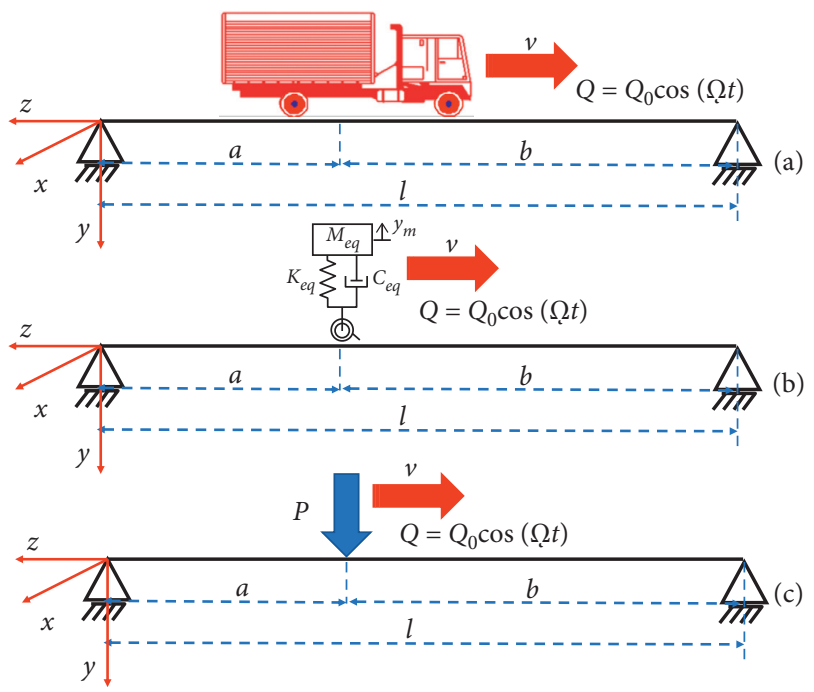

FIGURE 2: Single beam is under load moving with velocity $v$ along the beam bar.

$$
\begin{aligned}
y= & \left.\frac{P l^{3}}{E J \pi^{4}} \sum_{i=1}^{i=\infty} \sin \frac{i \pi x}{l}\left\{\frac{\sin (i \pi v / l+\Omega) t}{i^{4}-(\beta+i \beta)^{2}}+\frac{\sin (i \pi v / l-\Omega) t}{i^{4}-(\beta-i \beta)^{2}}\right\}\right\} \\
& -\frac{P l^{3}}{E J \pi^{4}} \sum_{i=1}^{i=\infty} \sin \frac{i \pi x}{l}\left\{\frac{\alpha}{i}\left(\frac{\sin i^{2} \pi^{2} a t / l^{2}}{-i^{2} \alpha^{2}+\left(i^{2}-\beta\right)^{2}}+\frac{\sin i^{2} \pi^{2} a t / l^{2}}{-i^{2} \alpha^{2}+\left(i^{2}+\beta\right)^{2}}\right)\right\},
\end{aligned}
$$

in which $\alpha=v l / \pi a ; \quad \beta=\tau / \tau_{2} ; \tau=2 l^{2} / \pi a ; \tau_{1}=l / v ;$ and $\tau_{2}=2 \pi / \Omega$. The nondamped free vibration of a single support beam has the following form:

$$
y=\sum_{i=1}^{i=\infty} \sin \frac{i \pi z}{l}\left(C_{i} \cos p_{i} t+D_{i} \sin p_{i} t\right),
$$

where $C_{i}$ and $D_{i}$ are constants and $p_{i}$ is the $i^{\text {th }}$-specific frequency in the following equation:

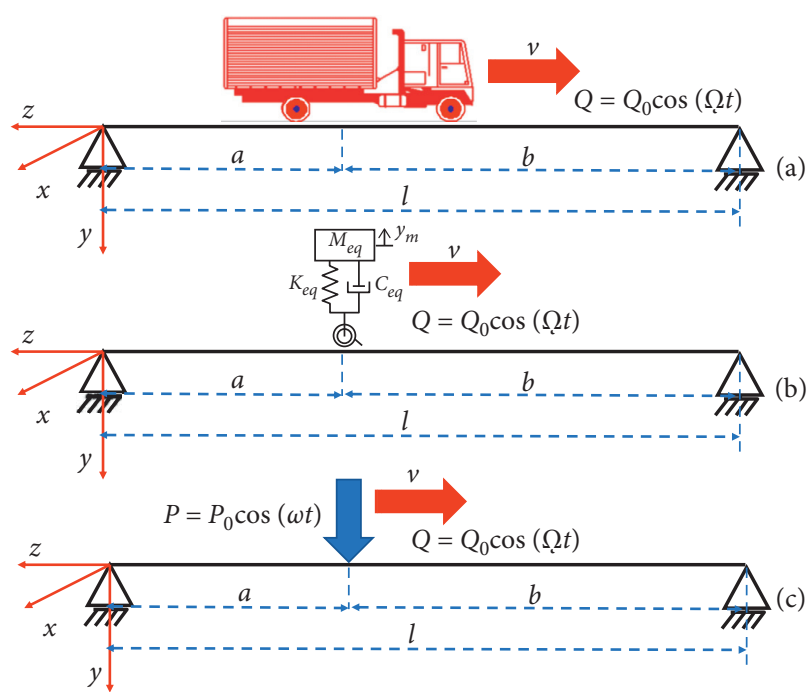

FIGURE 3: Single beam is under the harmonically variable load moving with velocity $v$ along the beam bar.

$$
p_{i}=\left(\frac{i \pi}{l}\right)^{2} \sqrt{\frac{E J}{A \rho}} .
$$

This study introduces the concept of "dynamic coefficient" so as to determine the relationship between the structure's load impact and the specific vibration frequency, in order to evaluate the changes in bridge span structure during the vibration process. The dynamic coefficient model has demonstrated that this coefficient is used for evaluating the bridge's load capacity through the deflection and the vibration frequency, as shown in equations (2) and (3), and the abridged model of the dynamic coefficient, as shown in the following equation:

$$
\begin{aligned}
\delta=1 & +\frac{Q}{P} \frac{\omega_{(1)}^{2}}{\Omega^{2}} \frac{1}{\left(\omega_{(1)}^{2} / \Omega^{2}-1\right)^{2}+4\left(\omega^{2} / \Omega^{2}+\omega_{b}^{2} / \Omega^{2}\right)} \\
& \cdot\left\{\left[\left(\frac{\omega_{(1)}^{2}}{\Omega^{2}}-1\right)^{2}+4 \frac{\omega_{b}^{2}}{\Omega^{2}}\right]^{1 / 2}+2 \frac{\omega}{\Omega} e^{-\omega_{b} l /(2 v)}\right\},
\end{aligned}
$$

in which $\delta$ is the dynamic coefficient, $\omega$ is the excitation frequency of vehicle load, $\Omega$ is the excitation frequency of the load under the action of velocity $v, \omega_{(1)}$ is the first excitation frequency of vehicle load, and $\omega_{b}$ is the bending frequency.

\section{Results}

3.1. Building the Experimental Models. Considering the methods implemented by us, this study examines the actual model of the Thang Long Bridge, as shown in Figure 4, which has the following specifications: the bridge is $60 \mathrm{~m}$ long; it includes 5 spans, each span being $12 \mathrm{~m}$ long; it has a simple steel concrete; the span cross-section includes 5 steel I-beams with dimensions $550 \times 250 \times 9 \times 22 \mathrm{~mm}$; the abutments and pillars are made of reinforced concrete; the bridge deck for vehicles is made of reinforced concrete of thickness 


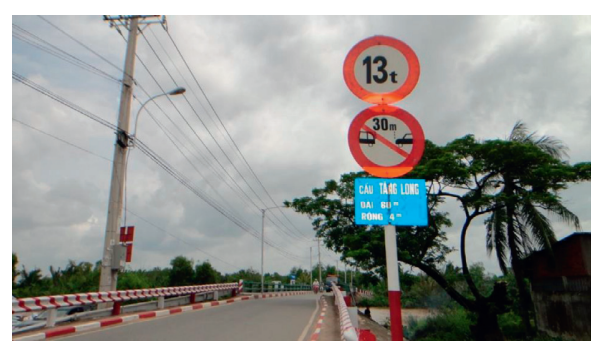

(a)

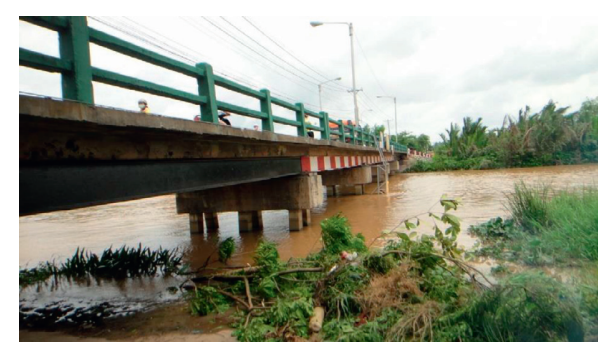

(b)

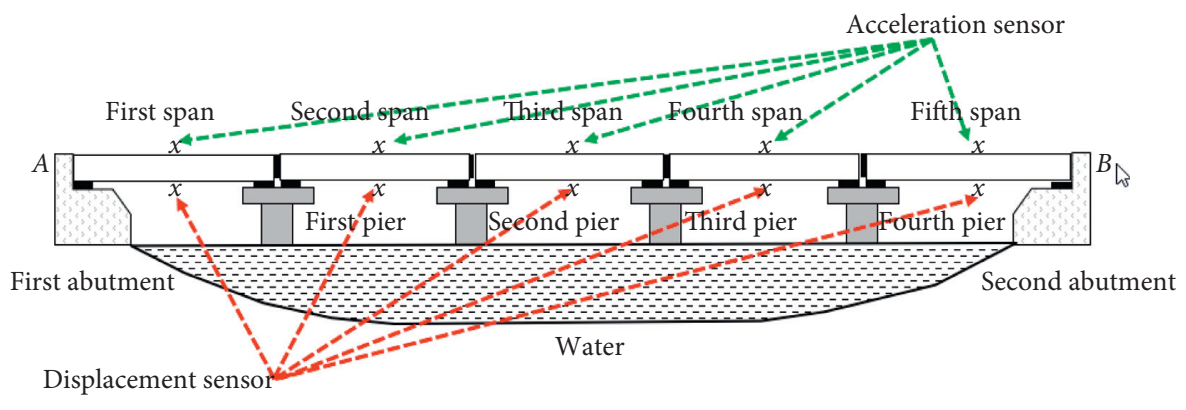

(c)

Figure 4: Actual model and longitudinal section of Thang Long Bridge.

$18 \mathrm{~cm}$; the bridge deck for pedestrians has a thickness of $20 \mathrm{~cm}$; the current operating load is 13 tons; and the bridge was built before 1990. The modeling process used in this study for the Thang Long Bridge, which is located on Thang Long Street, District 9, Ho Chi Minh City, is shown in Figure 5.

The bridge span is narrow; therefore, only one vehicle at a time can cross the bridge. The study models the Thang Long Bridge's mechanical force-bearing system, as shown in Figure 5, with a load consisting of two contributing components: the concentrated load $P$ and the moving load $Q_{0} \sin \Omega t$, with forced frequency $\Omega$, as originally analyzed.

In this research, the displacement signals are measured using a displacement sensor and the vibrations are measured with an accelerometer sensor. These sensors are permanently mounted and in contact with the beams' underside surfaces. The signal acquisition model is demonstrated in Figure 6.

In fact, the frequency of the constraining force $\Omega$ often depends on the mechanism and $Q$ depends on the velocity $v$ as in Table 1 . This study assumes that $Q=k * v^{2}$ and $\Omega=v / R$, where $Q$ is the amplitude of the harmonic force, $k$ is the experimental coefficient, $\Omega$ is the force's angular frequency, and $R$ is the wheel radius, as shown in Table 2 . This study will consider the change of load $P$ in the range of load limit for each type of vehicle, as in Table 3, due to the harmonically constraining force influenced by the vehicle structure.

With the parameters of the load $P$, the velocity $v$, and the frequency $\Omega$ of the constraining force, this study has built a workable model through the actual measurement process so as to determine the maximum deflection at given locations on the bridge span. This study has calculated the maximum stress value during the beams' vibration for the locations at which the deflection value is measured. The graph of the relationship between deflection and stress is given in Figure 7.

We can see the linear relationship between deflection and stress with the results in Figures 7 and 8. The linear regression equation is $y=6 \times 10^{-12} x-8 \times 10^{-9}$ with a correlation coefficient of $R^{2}=1$. When the load, velocity, and frequency of the constraining force change, the slope coefficient in Figure 8 remains constant; the deflection linearly increases when the load increases, regardless of the change in velocity or the change in frequency of the constraining force. The relationship between displacement and stress is often expressed as the structure's stress-deformation relationship. The results shown in Figure $9[25,26]$ were obtained from a study that used the linear material model to demonstrate the stress-deformation relationship of a concrete-reinforced beam structure with two required parameters: the elastic modulus of steel $E_{s}$ and the yield intensity of steel $f_{y}$. This concrete structure's simple stress-strain relationship curve has a multilinear isotropic form, proposed by Kachlakev [27], with two required parameters: the concrete's elastic modulus $E_{c}$ and its compressive strength $f_{c}^{\prime}$. In this material model, the von Mises criterion was used for determining the stress threshold so as to convert the concrete's linear behavior into nonlinear behavior, as shown in Figure 10, in which $\varepsilon_{0}$ is the stress at the peak of the material structure and $\beta$ is a material parameter depending on the shape of the stressdeformation diagram. The stress-deformation relationship is given by equation (7a). For the case of [25], the stress-deformation relationship is as shown in equation (7b).

$$
\begin{gathered}
\sigma=E \mathcal{\varepsilon}, \\
\sigma_{i}=E_{i} \varepsilon_{i} .
\end{gathered}
$$

With the models being studied in [25-27], we can see in the results that the relationship between stress and deformation is either always a linear function during a process $[28,29]$ or it is only a linear function in each defined space $[25,26]$. An evaluation model that exhibits both the influence of the elastic modulus $E$, which is a structural characteristic, 

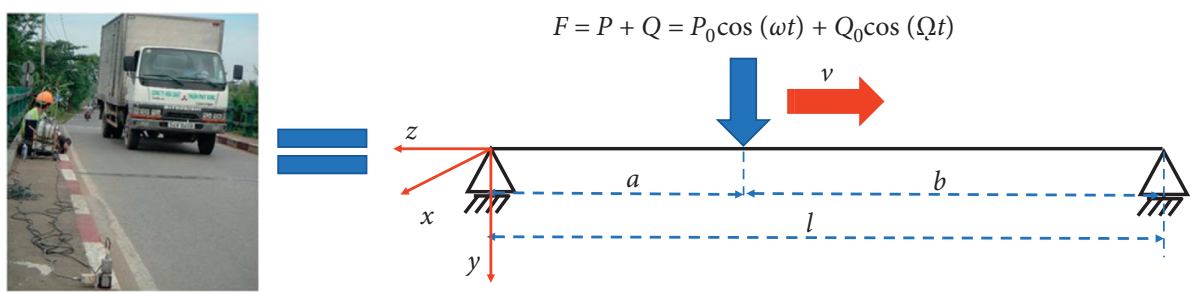

FIgURE 5: Actual load model of Thang Long Bridge.

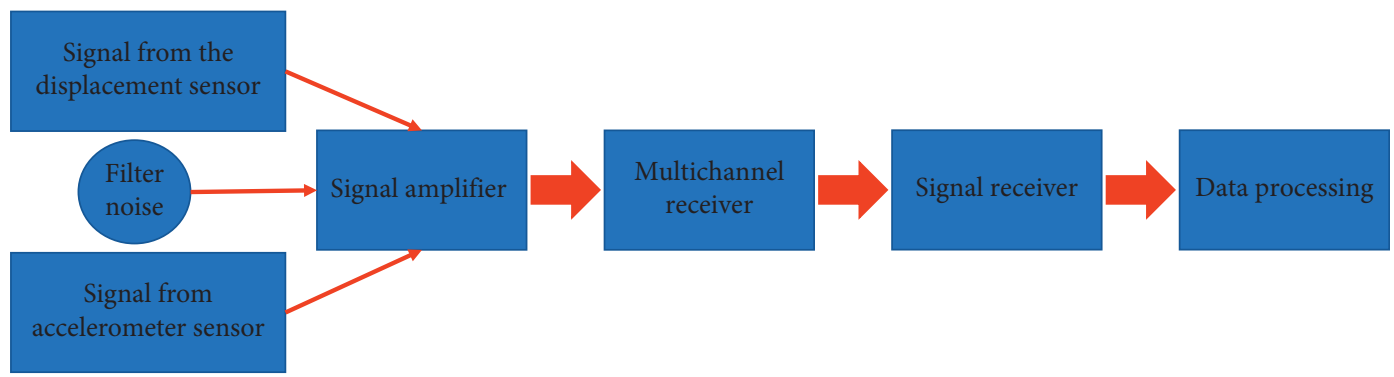

FIGURE 6: Diagram of data acquisition from the displacement sensor and vibration accelerometer.

TABle 1: Deflection data and elongation with load $P$, as the experimental velocity $v$ changes.

\begin{tabular}{lccc}
\hline$P$ & $v$ & Deflection $(\mathrm{m})$ & Stress $\left(\mathrm{N} / \mathrm{m}^{2}\right)$ \\
\hline 5,700 & 13 & 0.0056461 & $9.93 \times 10^{8}$ \\
5,800 & 6 & 0.0052025 & $9.15 \times 10^{8}$ \\
5,900 & 6 & 0.0052897 & $9.31 \times 10^{8}$ \\
6,100 & 6 & 0.0054634 & $9.61 \times 10^{8}$ \\
6,200 & 14 & 0.0066553 & $1.17 \times 10^{8}$ \\
6,500 & 6 & 0.0058087 & $1.02 \times 10^{9}$ \\
7,100 & 15 & 0.0071237 & $1.25 \times 10^{9}$ \\
8,200 & 13 & 0.0080203 & $1.41 \times 10^{9}$ \\
8,300 & 15 & 0.0083693 & $1.47 \times 10^{9}$ \\
8,500 & 8 & 0.0079308 & $1.40 \times 10^{9}$ \\
8,600 & 8 & 0.0080177 & $1.41 \times 10^{9}$ \\
8,800 & 6 & 0.0086454 & $1.52 \times 10^{9}$ \\
9,000 & 8 & 0.0083818 & $1.47 \times 10^{9}$ \\
10,100 & 9 & 0.01011 & $1.78 \times 10^{9}$ \\
10,200 & 8 & 0.0094648 & $1.67 \times 10^{9}$ \\
10,300 & 9 & 0.010372 & $1.82 \times 10^{9}$ \\
10,400 & 4 & 0.010212 & $1.80 \times 10^{9}$ \\
10,500 & 5 & 0.010266 & $1.81 \times 10^{9}$ \\
10,600 & 3 & 0.010262 & $1.81 \times 10^{9}$ \\
10,900 & 16 & 0.010373 & $1.82 \times 10^{9}$ \\
11,000 & 5 & 0.010795 & $1.90 \times 10^{9}$ \\
11,200 & 5 & 0.010946 & \\
\hline & & & $93 \times 10^{9}$ \\
\hline
\end{tabular}

and the antiviscosity coefficient $C$, which is a characteristic property of the material, has not yet been constructed.

\subsection{Relationship of Dynamic Parameters}

3.2.1. Relationship between Deflection and Vibration Acceleration. For the change of each load $P$, this study gets the results of both maximum deflection and maximum acceleration. When the velocity $v$ changes in the model, this study changes the velocity $v$ from $6 \mathrm{~m} / \mathrm{s}$ to $16 \mathrm{~m} / \mathrm{s}$ in order to
TABLE 2: Load parameters corresponding to different radii of vehicle wheels.

\begin{tabular}{lcc}
\hline Wheel radius $R(\mathrm{~m})$ & Load index & Weight $(\mathrm{kg})$ \\
\hline 0.330 & 83 & 487 \\
0.356 & 88 & 560 \\
0.381 & 96 & 710 \\
0.406 & 100 & 800 \\
0.432 & 104 & 900 \\
0.457 & 108 & 1,000 \\
0.483 & 109 & 1,030 \\
0.508 & 110 & 1,060 \\
0.533 & 111 & 1,090 \\
0.559 & 112 & 1,120 \\
\hline
\end{tabular}

TABle 3: Increased range of $P$ force value corresponding to each type of wheel radius.

\begin{tabular}{lc}
\hline$R$-wheel radius $(\mathrm{m})$ & $P$ value $(\mathrm{N})$ \\
\hline 0.008382 & $4,500-4,800$ \\
0.009042 & $4,800-5,600$ \\
0.009677 & $5,600-7,100$ \\
0.010312 & $7,100-8,000$ \\
0.010973 & $8,000-9,000$ \\
0.011608 & $9,000-10,000$ \\
0.012268 & $10,000-10,300$ \\
0.012903 & $10,300-10,600$ \\
0.013538 & $10,600-10,900$ \\
0.014199 & $10,900-11,200$ \\
\hline
\end{tabular}

either simplify the simulation process or conform to the bridge inspection standards.

We can see from the graphs shown in Figures 11(a)-11(f) that the variable relationship between deflection and acceleration at different load levels is relatively similar in terms of shape. Generally, when the acceleration increases, the deflection also increases and the difference in loads may be due to the masses of the loads that have influenced the beam's vibration 


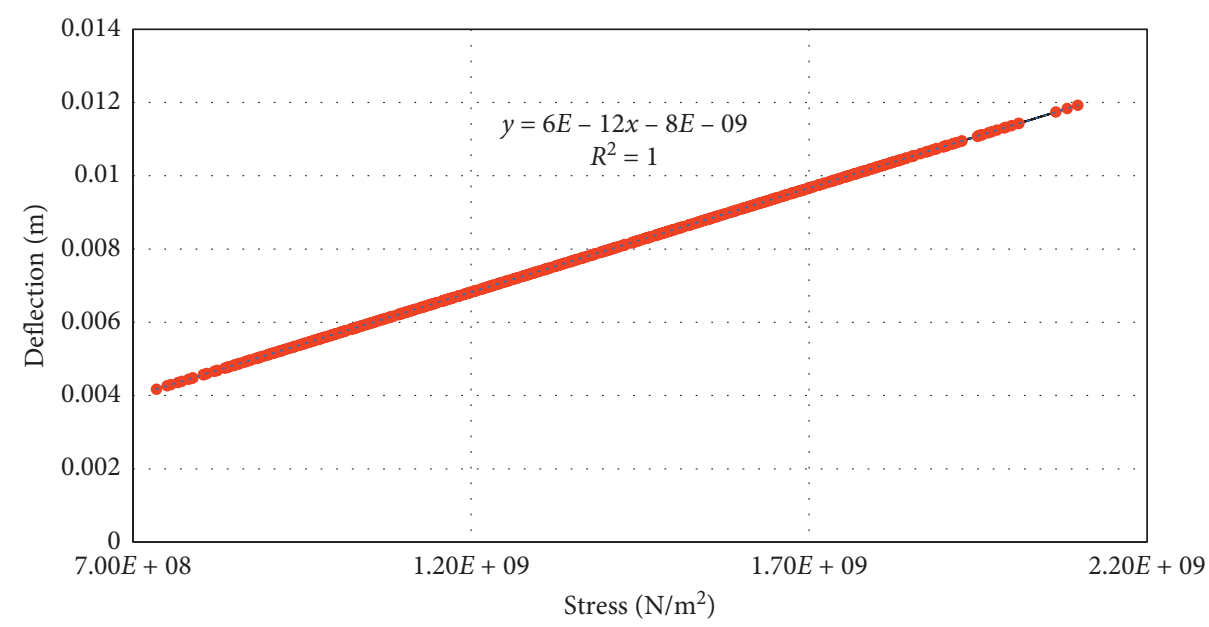

FIGURE 7: Graph showing the relationship between deflection and stress.

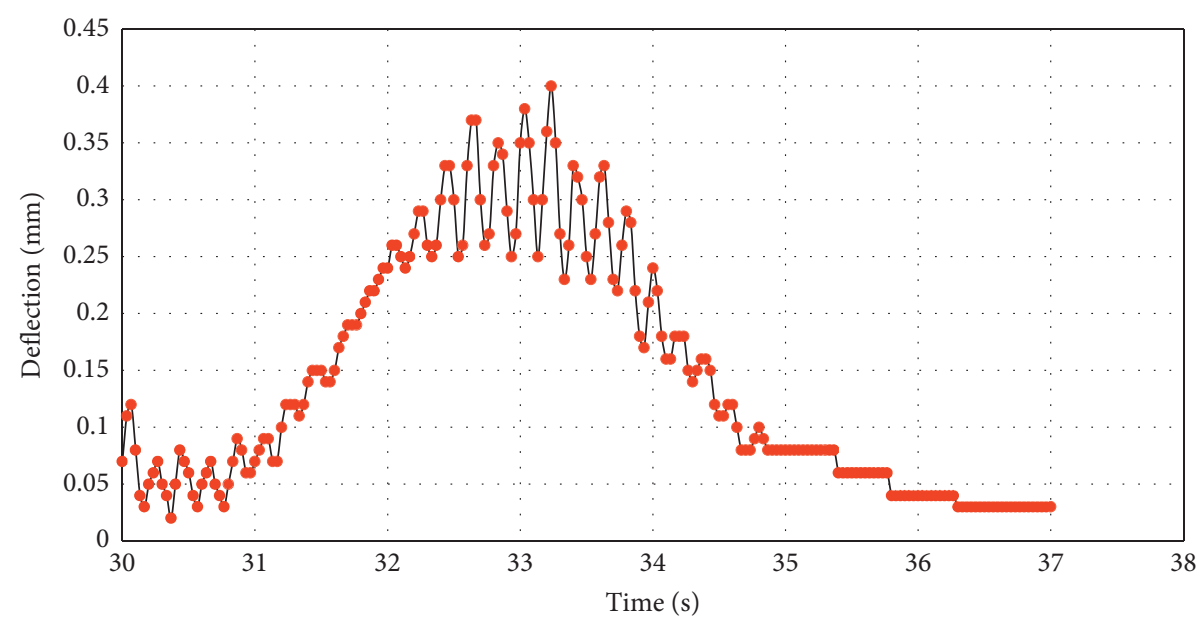

Figure 8: Signal deflection over time.

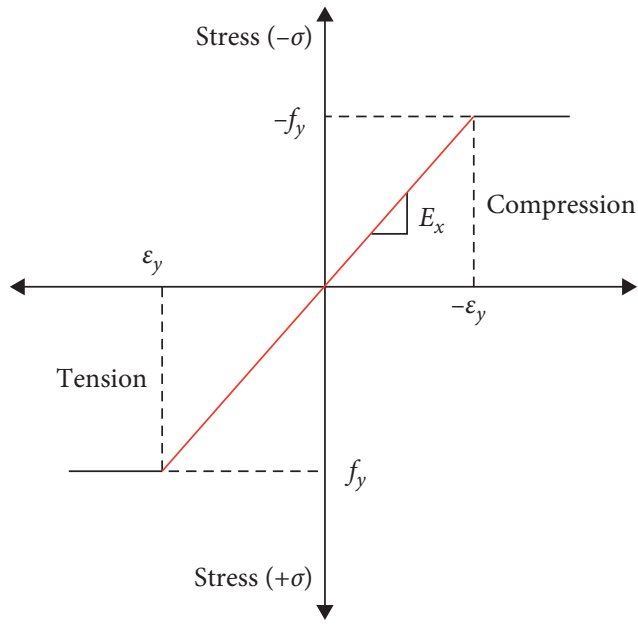

(a)

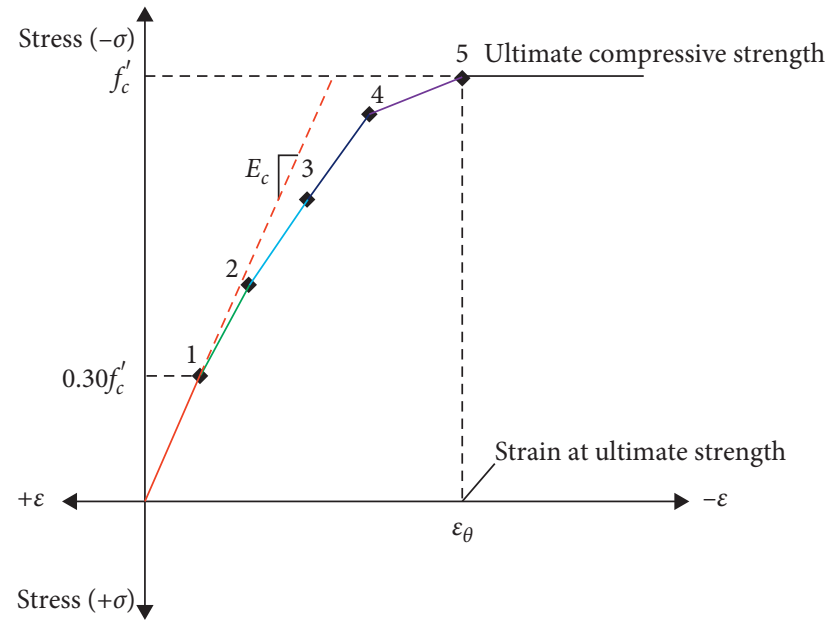

(b)

FIGURE 9: Stress-deformation relationship between reinforcement and concrete beams' concrete [25] and [26]. 


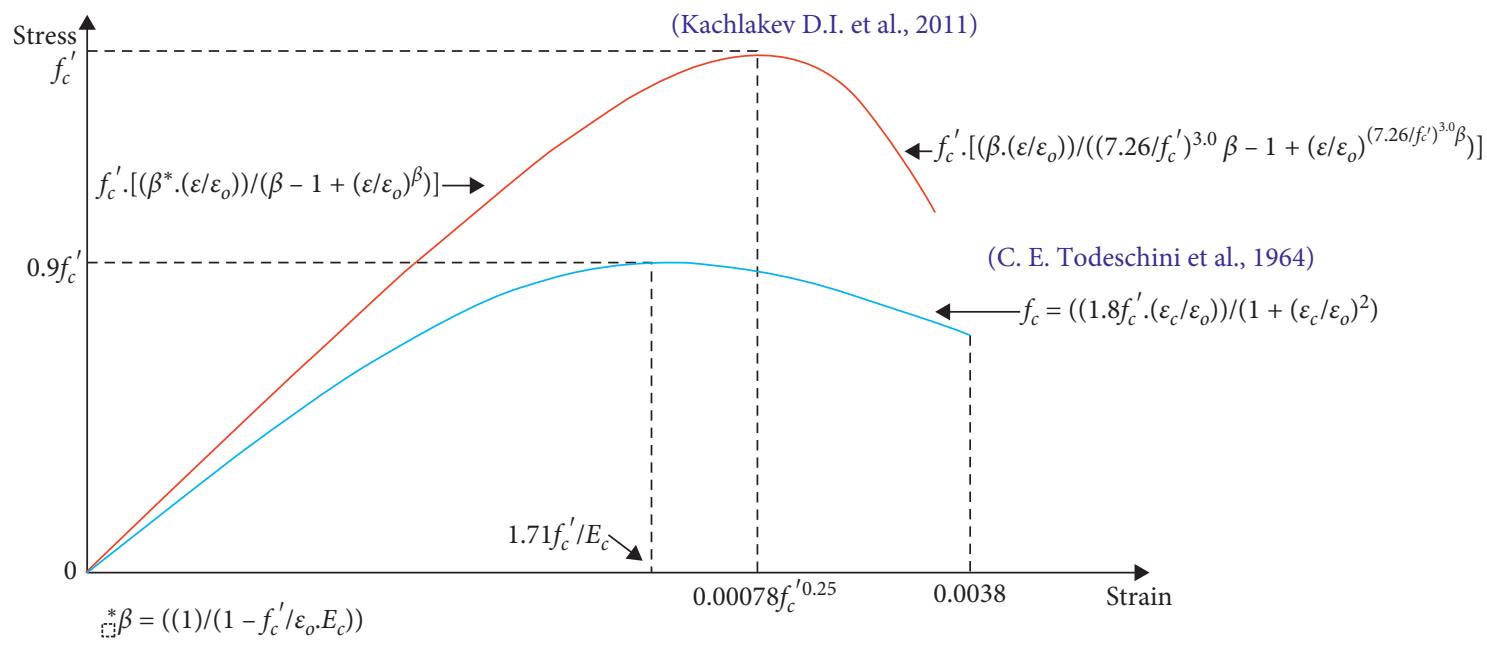

FIgURE 10: Concrete stress-strain models [27] and [28].

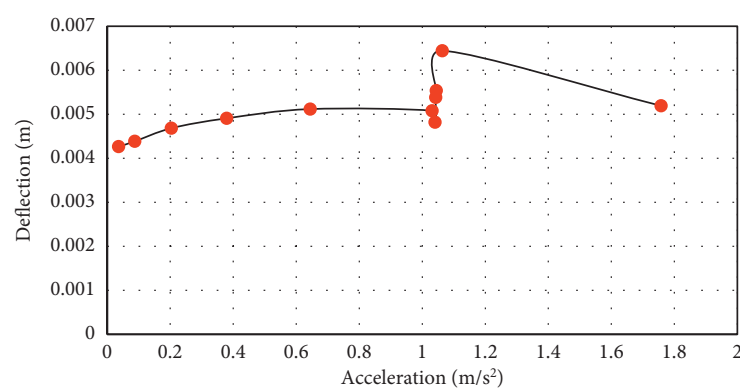

(a)

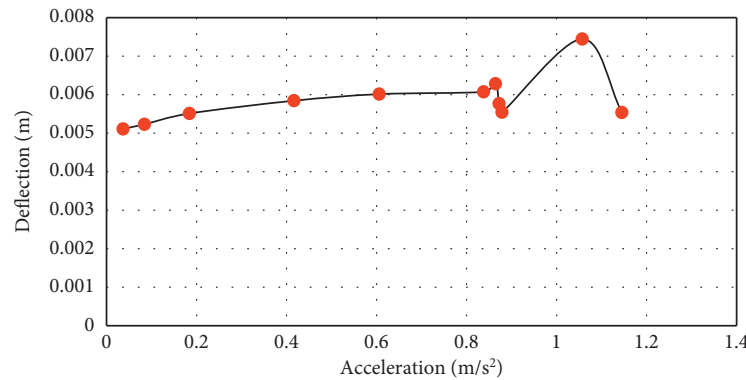

(c)

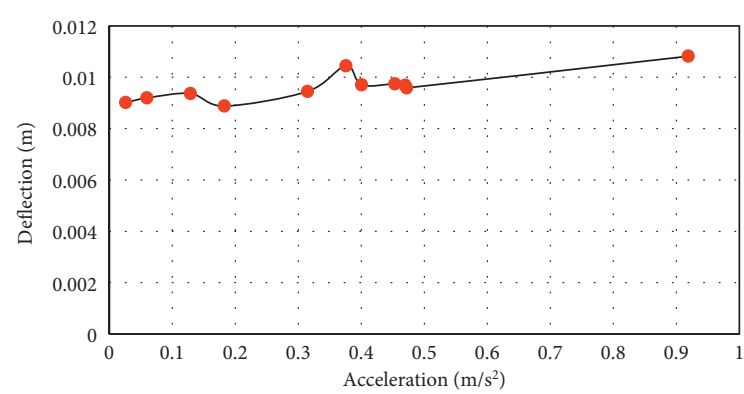

(e)

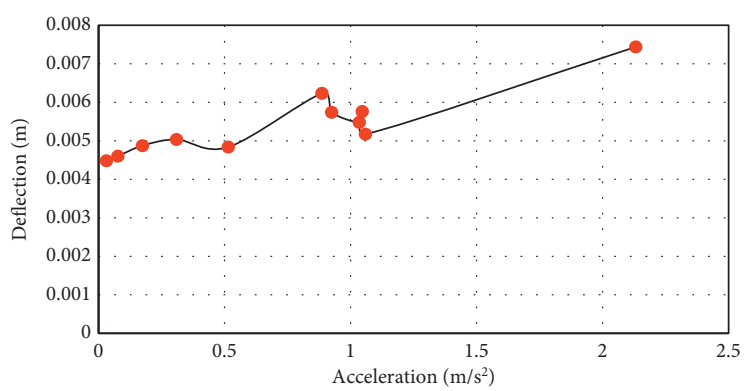

(b)

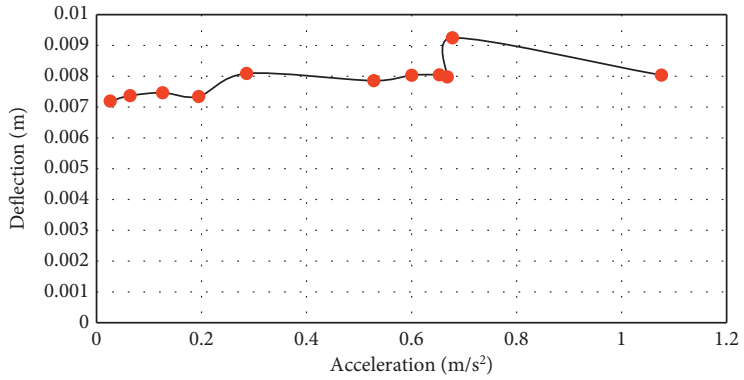

(d)

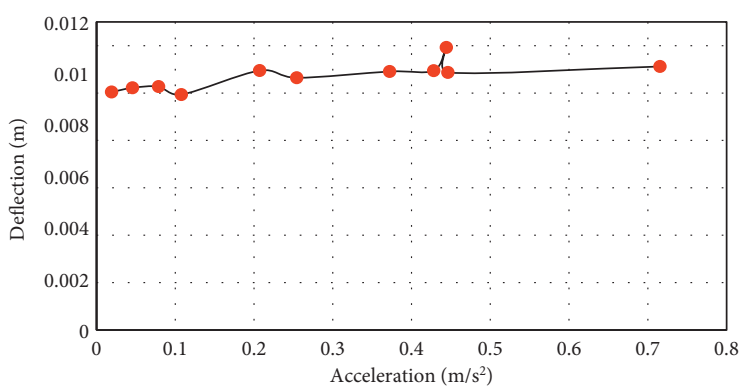

(f)

Figure 11: Graph of deflection versus acceleration with load of (a) $P=4,600 \mathrm{~N}$, (b) $P=4,900 \mathrm{~N}$, (c) $P=5,600 \mathrm{~N}$, (d) $P=8,000 \mathrm{~N}$, (e) $P=10,00$ $\mathrm{N}$, and (f) $P=11,200 \mathrm{~N}$, all enclosed with the change of velocity $v$.

frequencies according to equation (6). Thus, when the speed changes from $6 \mathrm{~m} / \mathrm{s}$ to $16 \mathrm{~m} / \mathrm{s}$ with the same $P$ load value, the study gets both the maximum deflection in this speed range and the frequency of the corresponding coercive force. From this, the study gets a graph that demonstrates the relationship between the deflection and the coercive force frequency 


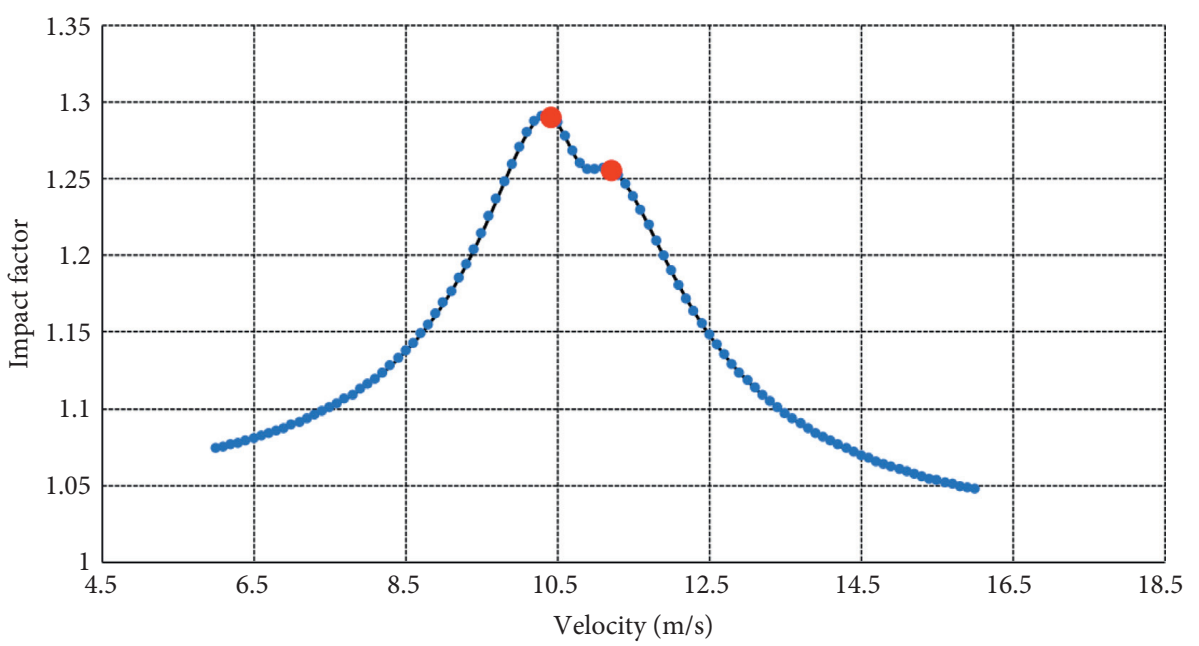

FIgURE 12: Relationship between the dynamic coefficient and velocity.

corresponding to the load $P$, as shown in Figures 11(a)-11(f), where the deflection reaches the maximum value for the case in which the vibration gradually approaches closer to the beam's first specific frequency.

\subsubsection{Building the Relationship between the Dynamic Co-} efficient and the Excitation Conditions. The curve has demonstrated the relationship between the dynamic coefficient $\delta$ and the velocity $v$, as represented in equation (6). When the force $P$ is constant, this study shows a dynamic coefficient $\delta$ corresponding to each velocity $v$, with $v$ varying from $6 \mathrm{~m} / \mathrm{s}$ to $16 \mathrm{~m} / \mathrm{s}$. In the graph, the dynamic coefficient $\delta$ and the velocity $v$ appear as two neighboring peaks, the distance between the two peaks being about $1 \mathrm{~m} / \mathrm{s}$, as shown in Figure 12. This can be explained because $\delta$ is affected by $\Omega$ in equation (6). Theoretically, the larger the dynamic coefficient is, the closer the coercive force frequency will be to the system's specific frequency. When referring to the actual spectrum analysis graph for a bridge, the frequency graph of the free vibrations shows two frequency peaks, which is called the "beat" phenomenon. This will be clearly analyzed in the following points:

(1) The influence of $P$ on the dynamic coefficient of fixed $v$. Because of the fixed speed and the increased load, the dynamic coefficient $\delta$ increases due to the force $P$ affecting the beam's first natural frequency, according to equation (6). Therefore, when $P$ increases, the beam's specific frequency $\omega_{1}$ decreases, with a value close to the coercive frequency generated by the vehicle, and the dynamic coefficient $\delta$ also increases. Because of the increased load $P$, the dynamic coefficient $\delta$ also increases in each specified load interval. In Figure 13, each new segment will linearly increase and then a sudden decrease is shown at the segment's end. At that moment, the dynamic coefficient $\delta$ linearly increases according to the original relationship; this process continues in many different force intervals, forming a graph that is not entirely linear, according to the theory originally given. This can be explained: When the force $P$ increases, the dynamic coefficient $\delta$ linearly increases, but when $\Omega$ decreases, the dynamic coefficient $\delta$ also decreases because it corresponds to each frequency of the coercive force $\Omega$. At certain locations, the $\delta$ value suddenly decreases because the coercive force frequency $\Omega$ abruptly changes under the original sine-cosine period, as shown in Figures 14(a)-14(f).

Table 4 shows that in the experimental model, the slope coefficient $a$, which is calculated as the ratio of the dynamic coefficient $\delta$ to the coercive force $\Omega$, is nearly constant during the experiment process. This can be explained by the fact that the coefficient $a$ does not depend on the angular frequency of the coercive force at constant velocity. In addition, when the coercive force frequency $\Omega$ increases, the coefficient of $b$ decreases. Table 4 shows the result that the more the $\Omega$ decreases in value, the faster the coefficient of $b$ increases. When the actual speed of the experimental model is $v=9 \mathrm{~m} / \mathrm{s}$, the relationship between the load $P$ and the dynamic coefficient $\delta$ given by the equation $\delta=a P+b$ is $\delta=0.000003 * P+1.041517$. In this experiment, the average deviation for coefficient $a$ is 0 , and for coefficient of $b$, it is 0.004117 . With this deviation level, the obtained results have given a high convergence.

(2) The influence of $P$ impacted on the dynamic coefficient in the case of changed velocity $v$.

With the increase in speed, the load value increases and the $\delta$ value also increases in each specified load interval. However, when all load ranges are considered in the same graph, the $\delta$ value tends to decrease, as shown in Figure 15. This study can see the conformity with equation (6) when the $P$ load value is in inverse ratio to the $\delta$ coefficient. This is similar to the previous survey, which showed that when the speed increases, the dynamic coefficient in each $P$ value segment increases and the $\delta$ value increases linearly, as shown in Figures 16(a)-16(e). 


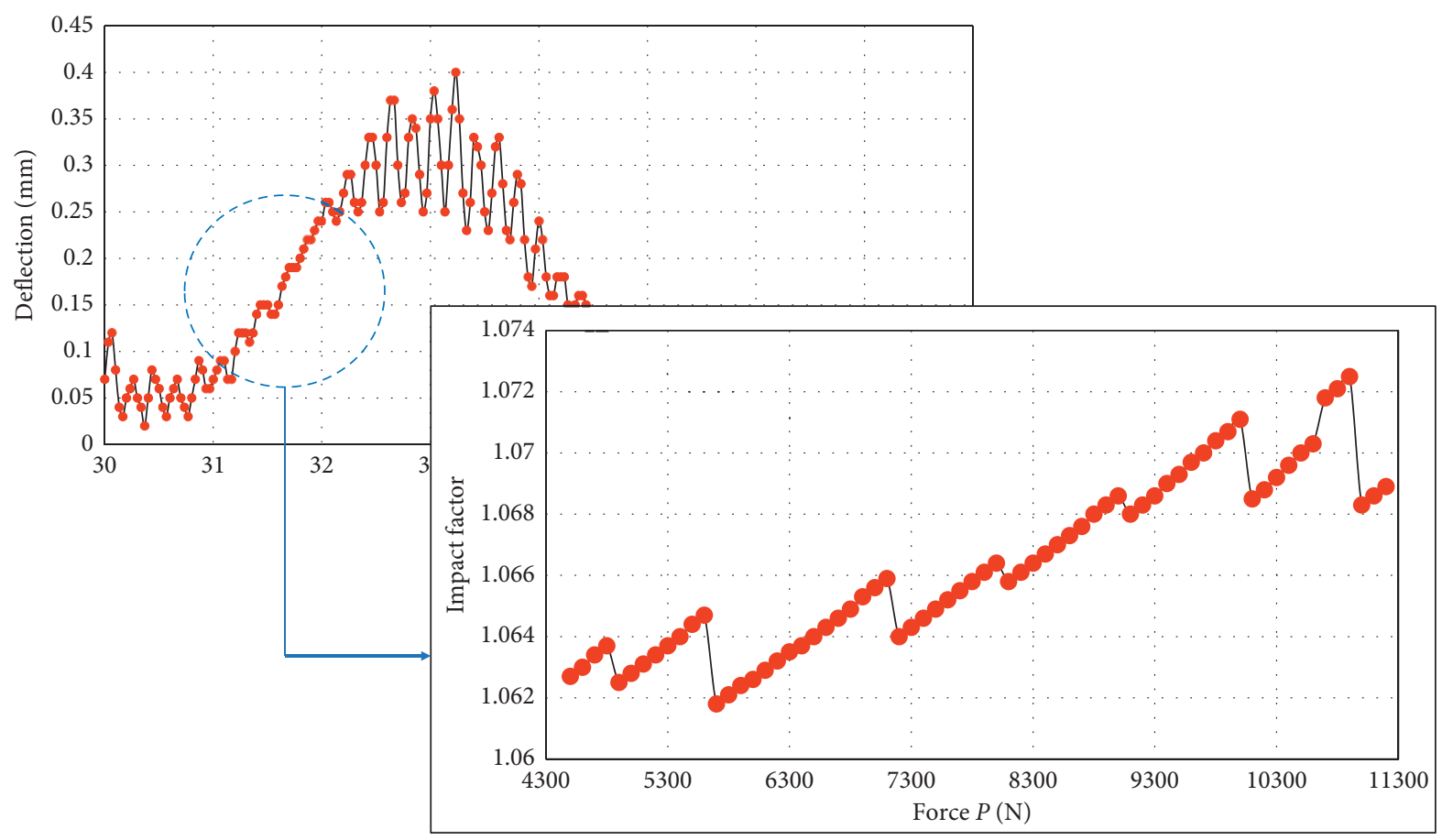

FIGURE 13: Graph showing relationship between $P$ and $\delta$ corresponding to $v=9 \mathrm{~m} / \mathrm{s}$.

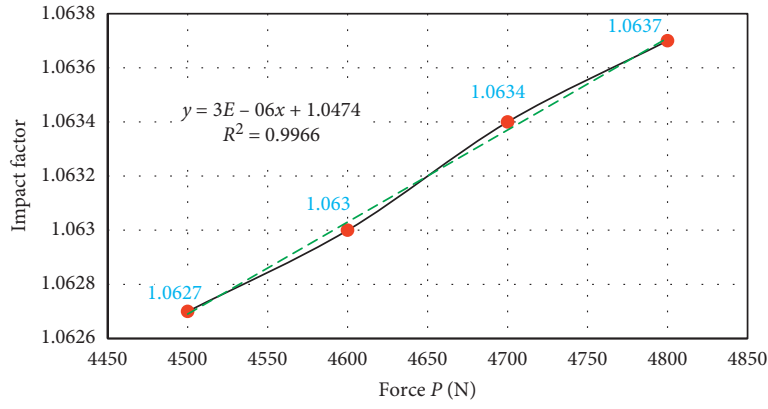

(a)

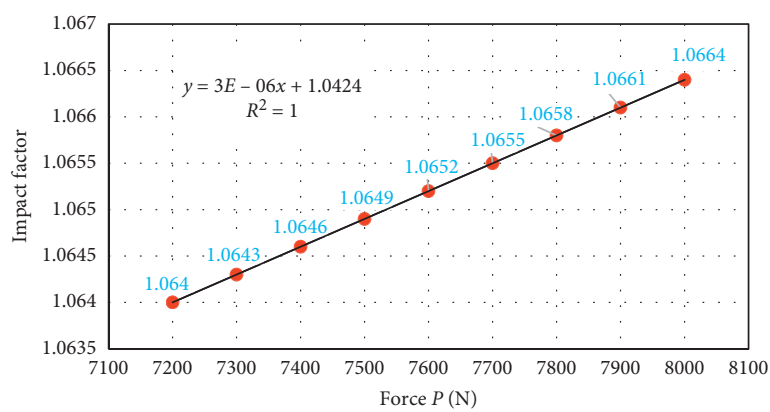

(c)

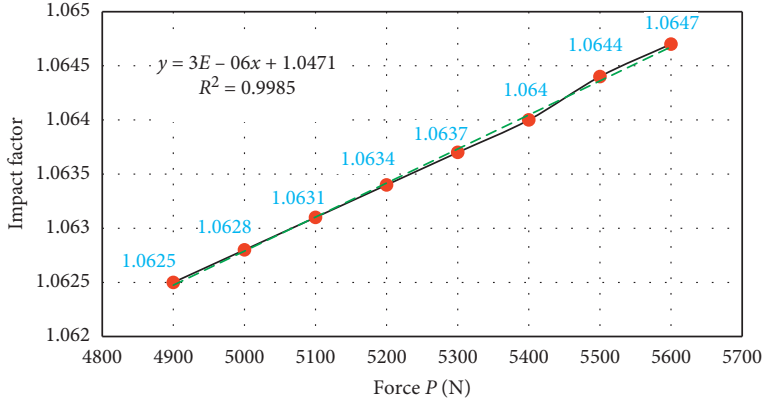

(b)

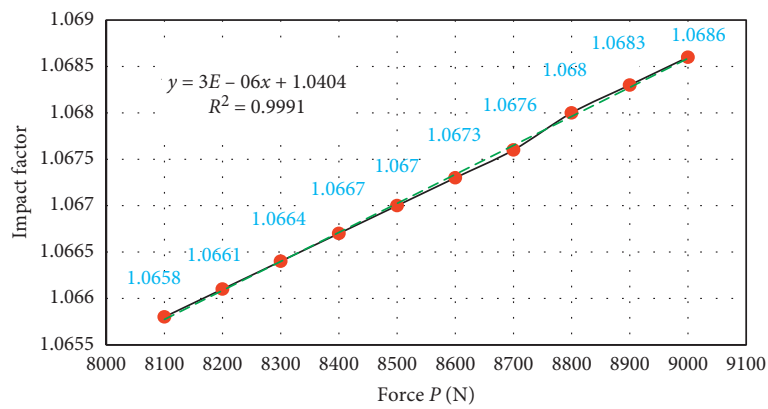

(d)

FIgURE 14: Continued. 


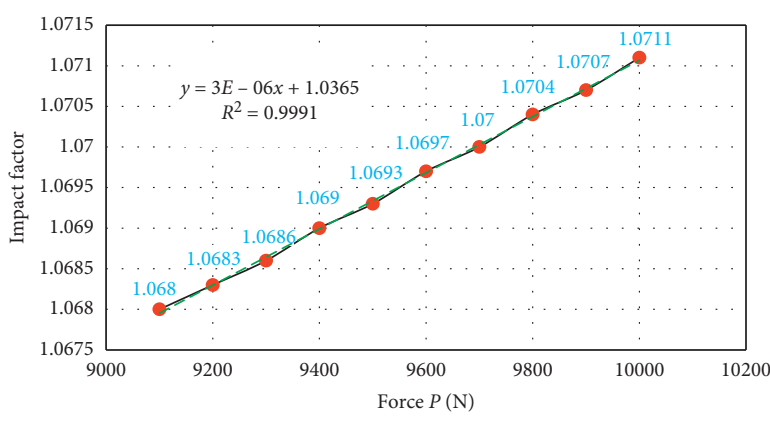

(e)

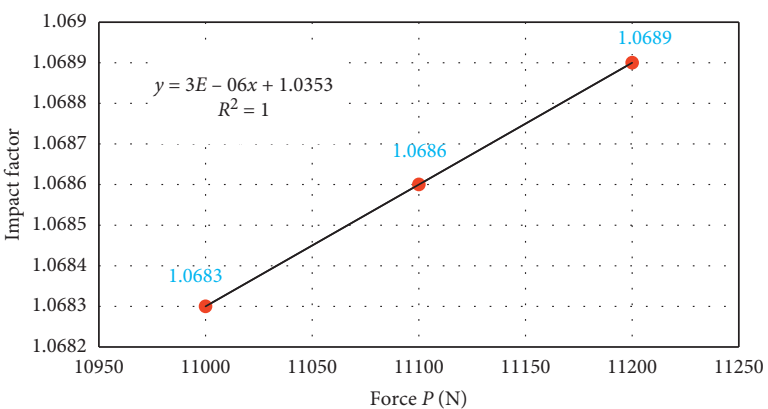

(f)

Figure 14: $\delta$ value graph when force $P$ ranges (a) from $4,500 \mathrm{~N}$ to $4,800 \mathrm{~N}$ with $\Omega=19.47209 \mathrm{rad} / \mathrm{s}$, (b) from $4,900 \mathrm{~N}$ to $5,600 \mathrm{~N}$ with $\Omega=18.55288 \mathrm{rad} / \mathrm{s}$, (c) from $7,200 \mathrm{~N}$ to $8,000 \mathrm{~N}$ with $\Omega=15.7784 \mathrm{rad} / \mathrm{s}$, (d) from $8,100 \mathrm{~N}$ to $9,000 \mathrm{~N}$ with $\Omega=15.39646 \mathrm{rad} / \mathrm{s}$, (e) from $9,100 \mathrm{~N}$ to $10,000 \mathrm{~N}$ with $\Omega=15.06402 \mathrm{rad} / \mathrm{s}$, and (f) from $9,100 \mathrm{~N}$ to $10,000 \mathrm{~N}$ with $\Omega=15.06402 \mathrm{rad} / \mathrm{s}$.

TABLE 4: Regression coefficients of $\delta=a P+b$ corresponding to each $\Omega$.

\begin{tabular}{lccc}
\hline$\Omega$ & $a$ & $b$ & $R^{2}$ \\
\hline 13.29787 & 0.000003 & 1.0353 & 1 \\
15.06402 & 0.000003 & 1.0365 & 0.9991 \\
15.39646 & 0.000003 & 1.0404 & 0.9991 \\
15.7784 & 0.000003 & 1.0424 & 1 \\
18.55288 & 0.000003 & 1.0471 & 0.9985 \\
19.47209 & 0.000003 & 1.0474 & 0.9966 \\
Average & 0.000003 & 1.041517 & 0.998883 \\
Average deviation & 0 & 0.004117 & 0.000889 \\
\hline
\end{tabular}

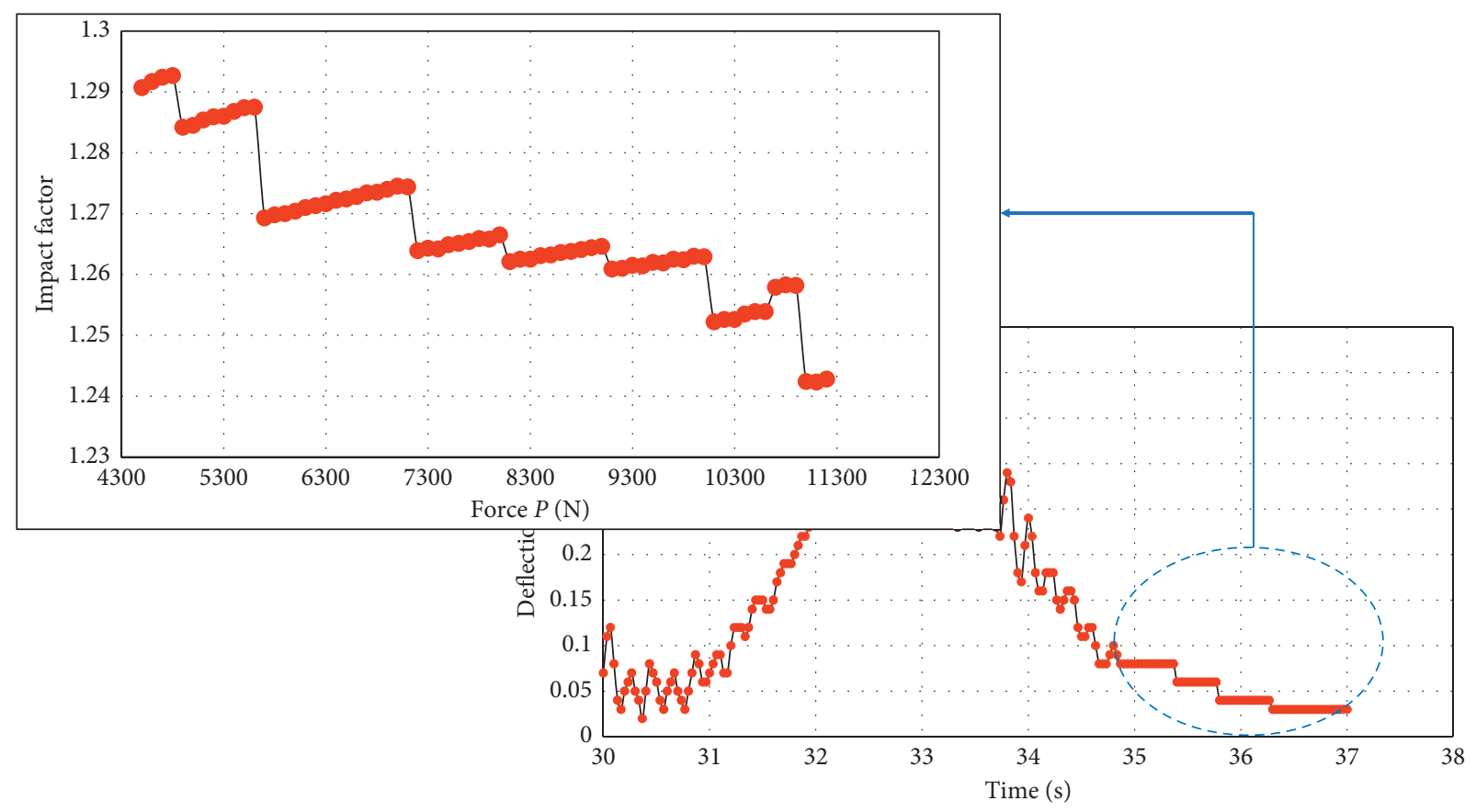

Figure 15: Graph showing relationship between $P$ and $\delta$ corresponding to $v$ varying from $6 \mathrm{~m} / \mathrm{s}$ to $16 \mathrm{~m} / \mathrm{s}$.

In Table 5, we can see that the equation showing the relationship between the dynamic coefficient $\delta$ and the load $P$, when the velocity $v$ changes, gives $\delta=0.000004^{*} P+$ 1.24804 with an average deviation of 0.0000016 for the coefficient of $a$ and of 0.009768 for the coefficient $b$. Thus, the value of the dynamic coefficient $\delta$ depends on both the velocity $v$ and the load $P$ as well as the frequency of coercive force $\Omega$. As $v$ increases, the $\delta$ value changes according to the linear relationship, as shown in the diagrams for $\delta$ and $v$. Corresponding to each $\Omega$ value, $P$ and $\delta$ increase linearly. 


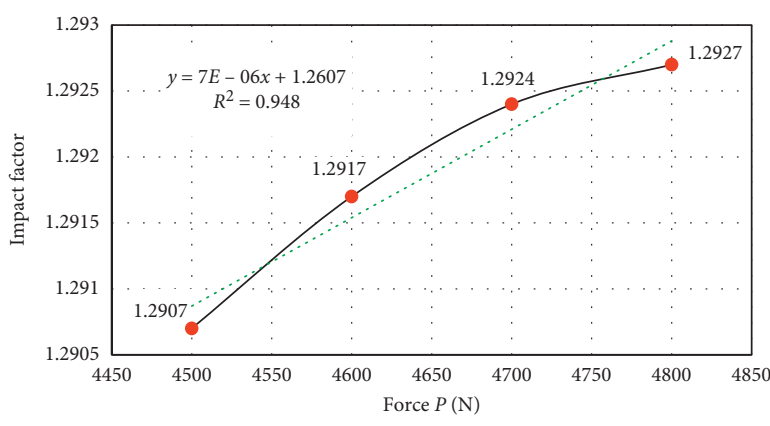

(a)

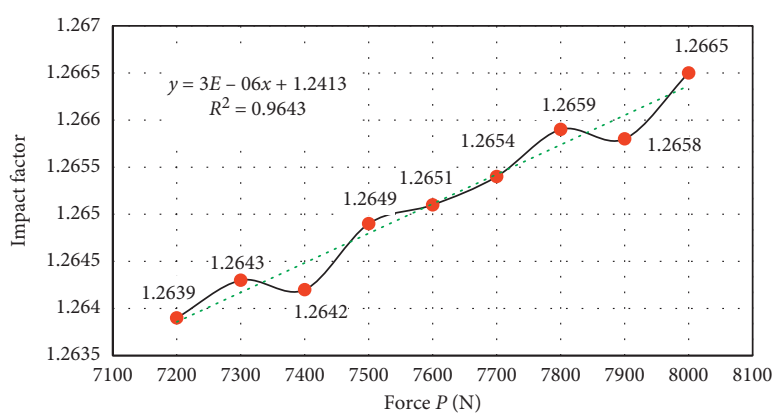

(c)

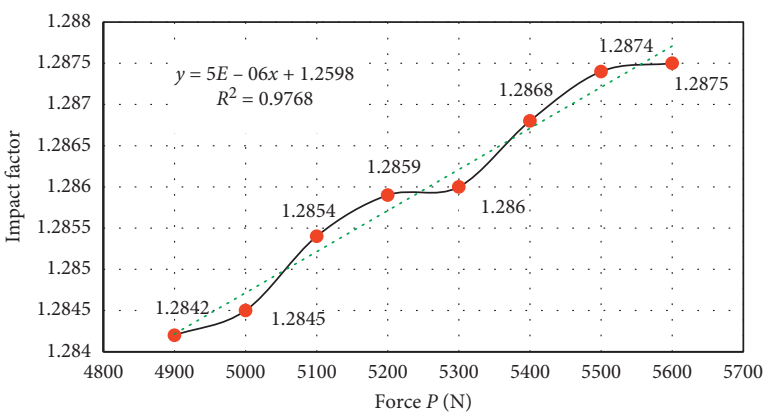

(b)

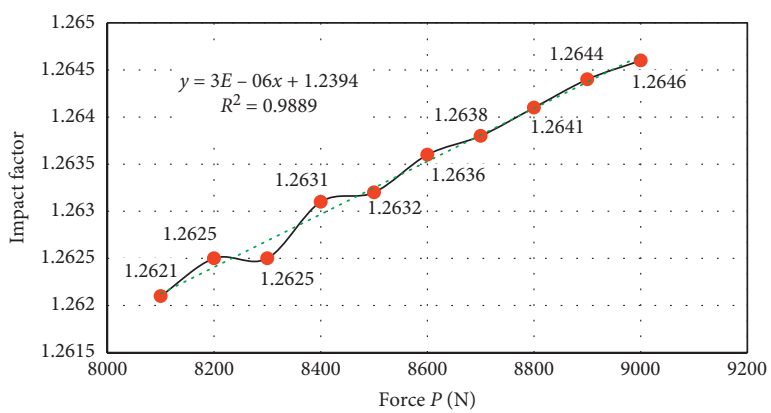

(d)

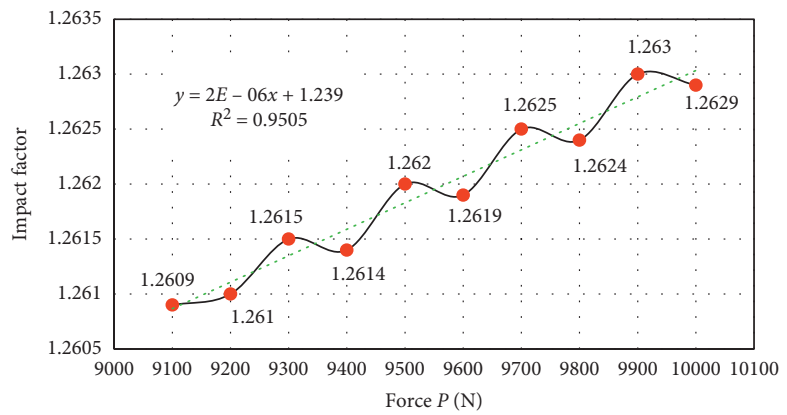

(e)

Figure 16: The diagram of the maximum $\delta$ value, when the velocity $v$ changes corresponding to $P$ (a) from $4,500 \mathrm{~N}$ to $4,800 \mathrm{~N}$, (b) from $4,900 \mathrm{~N}$ to $5,600 \mathrm{~N}$, (c) from $7,200 \mathrm{~N}$ to $8,000 \mathrm{~N}$, (d) from $8,100 \mathrm{~N}$ to $9,000 \mathrm{~N}$, and (e) from $9,100 \mathrm{~N}$ to $10,000 \mathrm{~N}$.

TABLE 5: Regression coefficients $\delta=a * P+b$ corresponding to each $P$ value range.

\begin{tabular}{lccc}
\hline$P(\mathrm{~N})$ & $a$ & $b$ & $R^{2}$ \\
\hline $4500-4800$ & 0.000007 & 1.2607 & 0.948 \\
$4900-5600$ & 0.000005 & 1.2598 & 0.9768 \\
$7200-8000$ & 0.000003 & 1.2413 & 0.9643 \\
$8100-9000$ & 0.000003 & 1.2394 & 0.9889 \\
$9100-10000$ & 0.000002 & 1.239 & 0.9505 \\
Average & 0.000004 & 1.24804 & 0.9657 \\
Average deviation & 0.0000016 & 0.009768 & 0.01372 \\
\hline
\end{tabular}

\section{Conclusion}

The experimental testing model has been applied in this study so as to find the relationships between the characteristic mechanical parameters during the measurement and testing process. From this manuscript, we can build an experimental model in the field that is most suitable for the actual moving load model, with some conclusions as follows:

(1) From either theory or experiment, the deflection values obtained under the load influence moving on the beams are relatively similar in terms of shape. As the deflection increases along with the velocity increase of the accelerating load, it can be seen that the difference in results with the varying loads may be due to the loads' mass influence on the beam's vibration frequencies. With a constant $P$ load value, but with speed increasing from $6 \mathrm{~m} / \mathrm{s}$ to $16 \mathrm{~m} / \mathrm{s}$, the study finds that the maximum deflection of frequency of the corresponding coercive force either remains unchanged or shows an insignificant change. From this study, we get the relationship between the deflection and the frequency of the corresponding coercive force. And, the deflection reaches the maximum value when the vibration 
frequency approaches closer to the beam's first specific frequency.

(2) Vehicle velocity has almost no influence on deflection values in both theoretical and experimental cases. It can be shown that for varying velocities, the differences in the results obtained for deflection values are insignificant and a structure's quality verification process is based primarily on deflection values.

(3) As $P$ increases, the beam's specific frequency $\omega_{1}$ decreases, so the dynamic coefficient $\delta$ increases accordingly. As the load $P$ increases, however, the dynamic coefficient $\delta$ increases only for each specified load interval. The value of the dynamic coefficient $\delta$ appears as a relationship, showing a linear increase at each segment, with a sudden decrease between segments. This process continues for many different force intervals, resulting in an incompletely linear diagram, according to the originally given theory. It can be shown that at certain locations, the $\delta$ value suddenly decreases because the coercive force frequency $\Omega$ suddenly changes, according to the initially given period.

\section{Data Availability}

The data used to support the findings of this study are included within the article.

\section{Conflicts of Interest}

The author declares no conflicts of interest.

\section{References}

[1] M. F. Van Staveren, J. P. M. Van Tatenhove, and J. F. Warner, "The tenth dragon: controlled seasonal flooding in long-term policy plans for the Vietnamese Mekong delta," Journal of Environmental Policy and Planning, vol. 20, no. 3, pp. 267$281,2018$.

[2] O. Husson, P. H. Verburg, M. Thanh Phung, and M. E. F. Van Mensvoort, "Spatial variability of acid sulphate soils in the plain of reeds, Mekong delta, Vietnam," Geoderma, vol. 97, no. 1-2, pp. 1-19, 2000.

[3] T. D. Nguyen, T. Q. Nguyen, T. N. Nhat, H. Nguyen-Xuan, and N. K. Ngo, "A novel approach based on viscoelastic parameters for bridge health monitoring: a case study of Saigon bridge in Ho Chi Minh City-Vietnam," Mechanical Systems and Signal Processing, vol. 141, Article ID 106728, 2020.

[4] T. Q. Nguyen, T. D. Nguyen, L. Q. Tran, and N. K. Ngo, “A new insight to vibration characteristics of spans under random moving load: case study of 38 bridges in Ho Chi Minh city Vietnam," Shock and Vibration, vol. 2020, Article ID 1547568, 20 pages, 2020.

[5] A. Atkinson, "Asian urbanisation," City, vol. 19, no. 6, pp. 857-874, 2015.

[6] N. T. Viet, T. T. Dieu, and N. Loan, "Current status of sludge collection, transportation and treatment in Ho Chi Minh city," Journal of Environmental Protection, vol. 4, no. 12, p. 40550, 2013.
[7] T. Q. Nguyen, H. C. Doan, L. C. Vuong, H. Nguyen-Xuan, and N. K. Ngo, "Fretting fatigue damage nucleation and propagation lifetime using a central point movement of power spectral density," Shock and Vibration, vol. 2020, Article ID 4985134, 16 pages, 2020.

[8] T. Q. Nguyen, T. D. Nguyen, H. Nguyen-Xuan, and N. K. Ngo, "A correlation coefficient approach for evaluation of stiffness degradation of beams under moving load," Computers, Materials \& Continua, vol. 61, no. 1, pp. 27-53, 2019.

[9] D. Agdas, J. A. Rice, J. R. Martinez, and I. R. Lasa, "Comparison of visual inspection and structural-health monitoring as bridge condition assessment methods," Journal of Performance of Constructed Facilities, vol. 30, no. 3, Article ID 04015049, 2016.

[10] B. F. Spencer, V. Hoskere, and Y. Narazaki, "Advances in computer vision-based civil infrastructure inspection and monitoring," Engineering, vol. 5, no. 2, pp. 199-222, 2019.

[11] A. Mufti, F. Raeisi, H. Khalid, A. Horosko, and B. Bakht, "A case for adding an inspection level related to structural health monitoring (SHM) for bridge evaluation," Canadian Journal of Civil Engineering, vol. 48, no. 4, pp. 1-14, 2021.

[12] S. Farhangdoust and A. Mehrabi, "Health monitoring of closure joints in accelerated bridge construction: a review of non-destructive testing application," Journal of Advanced Concrete Technology, vol. 17, no. 7, pp. 381-404, 2020.

[13] A. Sriram and S. Sritharan, "Quantifying bonding characteristics between UHPC and normal-strength concrete for bridge deck application," Journal of Bridge Engineering, vol. 24, no. 6, Article ID 04019041, 2019.

[14] S. Yehia, O. Abudayyeh, S. Nabulsi, and I. Abdelqader, "Detection of common defects in concrete bridge decks using nondestructive evaluation techniques," Journal of Bridge Engineering, vol. 12, no. 2, pp. 215-225, 2007.

[15] T. Q. Nguyen, L. C. Vuong, C. M. Le, N. K. Ngo, and H. Nguyen-Xuan, "A data-driven approach based on wavelet analysis and deep learning for identification of multiplecracked beam structures under moving load," Measurement, vol. 162, Article ID 107862, 2020.

[16] C. C. Tung, "Random response of highway bridges to vehicle loads," Journal of the Engineering Mechanics Division, vol. 93, pp. 73-94, 1967.

[17] R. Iwankiewicz and P. Śniady, "Vibration of a beam under a random stream of moving forces", Journal of Structural Mechanics, vol. 12, no. 1, pp. 13-26, 1984.

[18] H. S. Zibdeh and R. Rachwitz, "Moving loads on beams with general boundary conditions," Journal of Sound and Vibration, vol. 195, no. 1, pp. 85-102, 1996.

[19] S. F. Rastehkenari and M. Ghadiri, "Nonlinear random vibrations of functionally graded porous nanobeams using equivalent linearization method," Applied Mathematical Modelling, vol. 98, no. 2, pp. 847-1859, 2021.

[20] J. Zhan, F. Zhang, M. Siahkouhi, X. Kong, and X. He, "A damage identification method for connections of adjacent box-beam bridges using vehicle-bridge interaction analysis and model updating," Engineering Structures, vol. 228, Article ID 111551, 2020.

[21] Y. Zhang, L. Jiang, W. Zhou, Y. Feng, Z. Tan, and X. Chai, "Study of bridge-subgrade longitudinal constraint range for high-speed railway simply-supported beam bridge with CRTSII ballastless track under earthquake excitation," 
Construction and Building Materials, vol. 241, Article ID 118026, 2020.

[22] Z. Zhao, L. Yuan, and S. He, "Analysis of the failure mechanism of multi-beam steel-concrete composite bridge under car explosion," Advances in Structural Engineering, vol. 23, no. 3, pp. 538-548, 2020.

[23] W. Weaver, S. P. Timoshenko, and D. H. Young, Vibration Problems in Engineering, Wiley, Hoboken, NJ, USA, 5th edition, 1990.

[24] J. B. Roberts and P. D. Spanos, "Stochastic averaging: an approximate method of solving random vibration problems," International Journal of Non-Linear Mechanics, vol. 21, no. 2, pp. 111-134, 1986.

[25] T. T. Nguyen, H. H. Pham, Q. H. Luu, and H. C. Ho, "Finite element model and experiment verification of testing steelconcrete structures," in Proceedings of the Science and Technology Conference 12th, Rhodes, Greece, October 2011.

[26] A. J. Wolanski, "Flexural behavior of reinforced and prestressed concrete beams using finite element analysis," Master thesis, Marquette University, Milwaukee, WI, USA, 2004.

[27] D. I. Kachlakev, T. Miller, S. Yim, K. Chansawat, and T. Potisuk, "Finite element modeling of reinforced concrete structures strengthened with FRP laminates," SPR, 316, Oregon Department of Transportation, Salem, OR, USA, 2011.

[28] C. E. Todeschini, A. C. Bianchini, and C. E. Kesler, "Behavior of concrete columns reinforced with high strength steels," International Concrete Abstracts Portal, vol. 61, no. 6, pp. 704-716, 1964.

[29] T. H. Wee, M. S. Chin, and M. A. Mansur, "Stress-strain relationship of high-strength concrete in compression," Journal of Materials in Civil Engineering, vol. 8, no. 2, pp. 70-76, 1996. 